\title{
Principais agentes bacterianos associados à resistência antimicrobiana no tratamento de Infecções do Trato Urinário (ITU) em pacientes do sexo feminino
}

\author{
Main bacterial agents associated with antimicrobial resistance in the treatment of Urinary Tract \\ Infections (UTI) in female patients \\ Principales agentes bacterianos asociados a la resistencia a los antimicrobianos en el tratamiento de \\ las Infecciones del Tracto Urinario (ITU) en pacientes del sexo femenino
}

Recebido: 19/11/2021 | Revisado: 24/11/2021 | Aceito: 24/11/2021 | Publicado: 26/11/2021

\author{
Célia Moreno Lopes \\ ORCID: https://orcid.org/0000-0003-4382-749X \\ Universidade Nilton Lins, Brasil \\ E-mail: celialopes1992@gmail.com \\ Erick Frota Gomes Figueiredo \\ ORCID: https://orcid.org/0000-0002-6127-0544 \\ Universidade Nilton Lins, Brasil \\ E-mail: eick.figueiredo@uniniltonlins.edu.br
}

\begin{abstract}
Resumo
Conhecida como uma das infecções bacterianas mais comuns no ser humano, a infecção do trato urinário (ITU), afetam principalmente as mulheres. É uma patologia muito frequente na população, responsável por um grande número de consultas médicas e hospitalização, resultando em sérios problemas de saúde pública. Isto representa uma causa comum de prescrição de medicamentos para seu tratamento, como antibióticos que, quando feito de forma inadequada pode estar relacionado ao surgimento crescente de resistência bacteriana. O objetivo deste estudo foi realizar uma revisão de literatura sobre os principais agentes bacterianos associados à resistência antimicrobiana no tratamento de infecções do trato urinário (ITU) em pacientes do sexo feminino. Quanto aos aspectos metodológicos, o estudo é uma revisão integrativa da literatura, no período de 2015 a 2021, a partir de base de dados como Scientific Electronic Library, Lilacs (Scielo) Literatura Latino-Americana e do Caribe em Ciências da Saúde (Lilacs) por meio da plataforma da Biblioteca Virtual em Saúde (BVS), PubMed dados Medline e outras fontes físicas. Os resultados apontam que: 1) o uso correto e a devida orientação sobre os antibióticos são muito importantes; 2) a conscientização dos profissionais e da população sobre o uso racional, principalmente os antibióticos de amplo espectro, como as quinolonas, diminuindo a pressão na escolha dos antibióticos; 3) é necessário entender a resistência bacteriana em ambulatórios e internados com ITU, pois é importante monitorar as ações de resistência e evitar prescrições que não tenham um espectro antimicrobiano.
\end{abstract}

Palavras-chave: Agentes bacterianos; ITU; Resistência antimicrobiana.

\begin{abstract}
Known as one of the most common bacterial infections in humans, the urinary tract infection (UTI), mainly affects women. It is a very common pathology in the population, responsible for a large number of medical consultations and hospitalizations, resulting in serious public health problems. This represents a common cause of prescription drugs for its treatment, such as antibiotics, which, when done improperly, can be related to the growing emergence of bacterial resistance. The aim of this study was to conduct a literature review on the main bacterial agents associated with antimicrobial resistance in the treatment of urinary tract infections (UTI) in female patients. As for the methodological aspects, the study is an integrative literature review, from 2015 to 2021, based on databases such as Scientific Electronic Library, Lilacs (Scielo) Latin American and Caribbean Literature on Health Sciences (Lilacs) through the Virtual Health Library (VHL) platform, PubMed Medline data and other physical sources. The results show that: 1) the correct use and proper guidance on antibiotics are very important; 2) the awareness of professionals and the population about the rational use, especially broad-spectrum antibiotics, such as quinolones, reducing the pressure on the choice of antibiotics; 3 ) it is necessary to understand bacterial resistance in outpatient clinics and hospitalized with UTI, as it is important to monitor the actions of resistance and avoid prescriptions that do not have an antimicrobial spectrum.
\end{abstract}

Keywords: Bacterial agents; ITU; Antimicrobial resistance. 


\begin{abstract}
Resumen
Conocida como una de las infecciones bacterianas más comunes en los seres humanos, la infección del tracto urinario (ITU) afecta principalmente a las mujeres. Es una patología muy común en la población, responsable de un gran número de consultas médicas y hospitalizaciones, resultando en graves problemas de salud pública. Esto representa una causa común de los medicamentos recetados para su tratamiento, como los antibióticos, que, cuando se hacen de manera inadecuada, pueden estar relacionados con la creciente aparición de resistencias bacterianas. El objetivo de este estudio fue realizar una revisión de la literatura sobre los principales agentes bacterianos asociados a la resistencia a los antimicrobianos en el tratamiento de las infecciones del tracto urinario (ITU) en pacientes del sexo femenino. En cuanto a los aspectos metodológicos, el estudio es una revisión integradora de la literatura, de 2015 a 2021, con base en bases de datos como Biblioteca Electrónica Científica, Lilacs (Scielo) Literatura Latinoamericana y del Caribe en Ciencias de la Salud (Lilacs) a través de la Biblioteca Virtual en Salud (VHL), datos de PubMed Medline y otras fuentes físicas. Los resultados muestran que: 1) el uso correcto y la orientación adecuada de los antibióticos es muy importante; 2) la sensibilización de los profesionales y la población sobre el uso racional, especialmente de antibióticos de amplio espectro, como las quinolonas, reduciendo la presión sobre la elección de antibióticos; 3) es necesario comprender la resistencia bacteriana en consultas externas y hospitalizados con ITU, ya que es importante monitorear las acciones de resistencia y evitar prescripciones que no tengan espectro antimicrobiano.
\end{abstract}

Palabras clave: Agentes bacterianos; ITU; Resistencia antimicrobiana.

\title{
1. Introdução
}

Em suas abordagens Pereira \& Calhau (2016) define a infecção do trato urinário (ITU) como uma bacteriúria importante e sintomática, que cresce e se reproduz dentro do trato urinário. É uma doença que acontece em qualquer idade, sendo mais prevalente no sexo feminino. As mulheres em idade fértil preocupam principalmente a atenção em situação gravídica.

De acordo com Nóbrega (2015), a predominância de ITU em mulheres se intensifica com a idade, constatando-se que a bacteriúria está presente em 10\% a 15\% das mulheres na faixa etária entre 65 a 70 anos; em 15\% a 20\% nas mulheres acima de 80 . Por volta de $40 \%$ a $50 \%$ das mulheres retratam ao menos um episódio de ITU no decorrer da vida e $30 \%$ delas manifestam ITU recorrente.Conforme se observa, a ITU é ocorre com muita frequência em mulheres, responsável por um grande número de consultas médicas e hospitalização, resultando em sérios problemas de saúde. Isto representa uma causa comum de prescrição medicamentos que, quando feito de forma inadequada pode estar relacionado ao surgimento crescente de resistência bacteriana (Nóbrega, 2015).

A resistência bacteriana é o resultado da pressão seletiva decorrente do uso indiscriminado e extenso medicamentos e da capacidade dos patógenos se adaptarem a ambientes hostis. Algumas hipóteses têm sido propostas para aumentar a taxa de resistência, seja na Medicina, na produção de ração animal ou na agricultura. Medidas para eliminar a resistência bacteriana por meio da restrição do uso de antimicrobianos e seu uso racional ainda é um desafio para países com extenso território como o Brasil, com escassa equipe de vigilância para monitorar e controlar sua venda e uso (Barberino, 2021).

Justifica-se, portanto, a abordagem do tema por sua relevância, na medida em que a urocultura pode ajudar a identificar os principais fatores bacterianos, bem como aqueles que são mais resistentes aos antibióticos comumente usados para tratar infecções urinárias.

Diante disso, esta revisão tem por objetivo realizar uma revisão de literatura sobre os principais agentes bacterianos associados à resistência antimicrobiana no tratamento de infecções do trato urinário (ITU) em pacientes do sexo feminino. Para tanto, especificamente destaca gênero e a idade mais afetada na população; apresenta os principais agentes causadores ITU; e identifica a sensibilidade e resistência das bactérias causadoras da infecção aos agentes antibacterianos.

Assim, partir desses conhecimentos, espera-se oferecer informações importantes sobre os antibióticos mais eficazes nesse tratamento patológico, e possibilitar, com os resultados, contribuir com melhorar na qualidade da assistência médico hospitalar aos pacientes que enfrentam sintomas e recorrências de ITU. 


\section{Metodologia}

Trata-se de uma revisão integrativa da literatura que propõe analisar e buscar pesquisas relevantes que possibilitem sintetizar o conhecimento sobre o tema proposto, a fim de formular conclusões a partir dos estudos incluídos na revisão, além de indicar lacunas que necessitam ser preenchida com novos estudos (Mendes et al., 2021).

Num primeiro momento foram selecionados literatura e trabalhos científicos, a partir da base de dados do Scielo (Scientific Electronic Library), Lilacs (Literatura Latino-Americana e do Caribe em Ciências da Saúde) por meio da plataforma BVS (Biblioteca Virtual de Saúde), PubMed site de acesso da base de dados Medline e outras fontes físicas, utilizando os descritores: ITU, Agentes Bacterianos e Resistência.

Os critérios de inclusão para trabalhos foram os descritores mencionados, publicados em português no período de 2015 a 2021. Como critérios de exclusão, foram considerados: publicações em outros idiomas, editorias, revisões, indisponibilidade para a recuperação da publicação na íntegra e inadequação ao objeto de estudo.

Os dados do material selecionado foram analisados e discutidos durante o período de março a outubro de 2021, buscando a apresentação do objeto proposto. Após análise discussão dos artigos, apresentou-se os resultados de forma descritiva e complementar as ideias de cada autor.

O desenho metodológico para seleção dos artigos pode ser identificado na Figura 1.

Figura 1 - Ilustração representativa do processo metodológico da revisão integrativa da literatura.

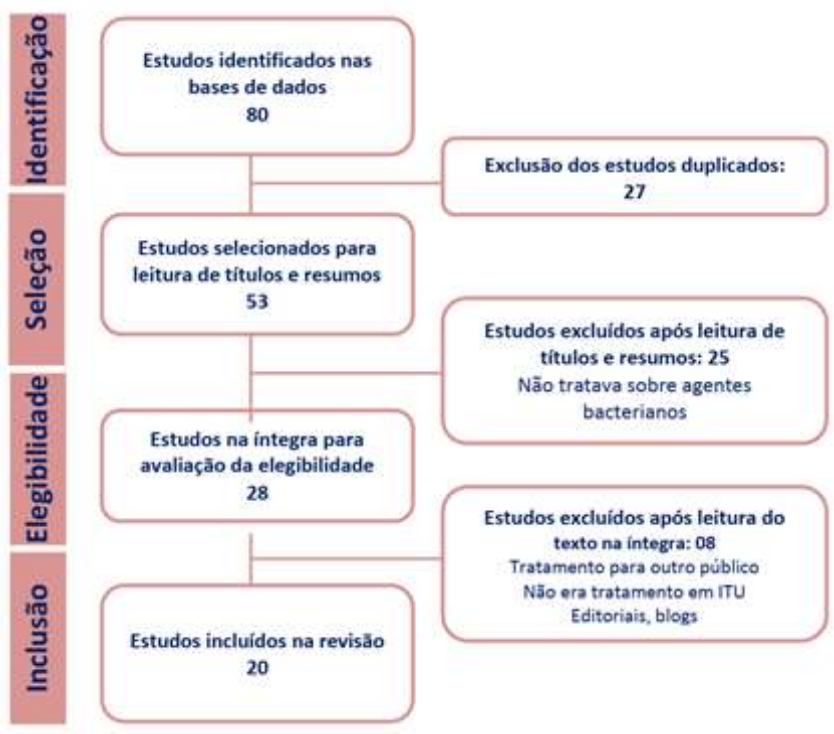

Fonte: Autora (2021).

\section{Resultados e Discussão}

Nesta revisão foram selecionados 20 artigos dos quais quatro (20,0\%) foi identificado na Scielo, dez (53,0\%) na Lilacs por meio da plataforma BVS, e cinco (27,0\%) na PubMed site de acesso da base de dados Medline. Desses, dez (53,0\%) tinham sido publicados em periódicos de enfermagem, quatro (20,0\%) em revistas interdisciplinares de saúde ecinco (27,0 \%) em revistas de outras áreas da saúde.

Todos os textos incluídos foram escritos em língua portuguesa. Em relação a categoria profissional dos autores, seis (40,0\%) artigos foram redigidos em parceria com enfermeiros, quatro (27,0\%), um (7,0\%) por médicos em parceria com enfermeiros e um $(7,0 \%)$ por nutricionista em parceria com enfermeiros. Em três $(20,0 \%)$ não foi possível identificar essa informação. Diante dos resultados encontrados após os critérios de exclusão e inclusão, desenvolveu-se um quadro com as características dos principais artigos selecionados, como descrito a seguir no Quadro 1. 
Quadro 1 - Quadro sinóptico segundo autor, título, local, ano e abordagem, 2021.

\begin{tabular}{|c|c|c|c|}
\hline Autor/Ano & Título & Objetivo & Principais resultados \\
\hline $\begin{array}{l}\text { Assis et al., } \\
2018 .\end{array}$ & $\begin{array}{l}\text { A incidência de infecções } \\
\text { no trato urinário: uma } \\
\text { análise documental de } \\
\text { prontuários }\end{array}$ & $\begin{array}{l}\text { Avaliar a frequência das principais } \\
\text { bactérias encontradas, avaliar o } \\
\text { perfil de resistência dos antibióticos } \\
\text { utilizados }\end{array}$ & $\begin{array}{l}\text { Os microrganismos mais proeminentes foram às bactérias Gram } \\
\text { negativas e oprincipal agente causador das infecções é a } \\
\begin{array}{l}\text { Escherichia coli presente em } 83,6 \% \text { das infecções } \\
\text { diagnosticadas. }\end{array}\end{array}$ \\
\hline $\begin{array}{l}\text { Barberino, } \\
2021\end{array}$ & $\begin{array}{l}\text { A incidência de infecções } \\
\text { no trato urinário: uma } \\
\text { análise documental de } \\
\text { prontuários. }\end{array}$ & $\begin{array}{l}\text { Avaliar o desempenho dos testes } \\
\text { laboratoriais rápidos para } \\
\text { diagnóstico das infecções não } \\
\text { complicadas do trato urinário } \\
\text { adquiridas na } \\
\text { comunidade. }\end{array}$ & $\begin{array}{l}\text { A amostra de casos de ITU era formada por } 342(83 \%) \text { adultos e } \\
69(17 \%) \text { crianças predominância do sexo feminino }(85 \%) \text {. Dos } \\
22 \text { antibióticos testados, a maior prevalência de resistência foi } \\
\text { encontrada para ampicilina-sulbactam }(41 \%) \text {, ampicilina ( } 49 \%) \text {, } \\
\text { cefalotina (33\%) e sulfametoxazol-trimetoprim } \\
(36 \%) \text {. }\end{array}$ \\
\hline $\begin{array}{l}\text { Barbosa e } \\
\text { Resende, 2018. }\end{array}$ & $\begin{array}{l}\text { Perfil do uso } \\
\text { indiscriminado de } \\
\text { medicamento da cidade de } \\
\text { Cordisburgo-MG. }\end{array}$ & $\begin{array}{l}\text { Traçar o perfil do uso } \\
\text { indiscriminado de medicamentos } \\
\text { em um grupo de adultos da cidade } \\
\text { de Cordisburgo - MG. }\end{array}$ & $\begin{array}{l}100 \% \text { possuem o hábito de se automedicarem e } 70 \% \text { desses } \\
\text { interromperam o uso após o desaparecimento dos sintomas, } \\
\text { podendo fazer com o que o organismo crie uma resistência } \\
\text { medicamentosa. Em relação aos medicamentos mais utilizados, } \\
\text { os analgésicos, anti-inflamatórios lideraram a pesquisa. }\end{array}$ \\
\hline $\begin{array}{l}\text { Brambilla, } \\
2019 .\end{array}$ & $\begin{array}{l}\text { Incidência de } \\
\text { microrganismos em } \\
\text { infecções no trato urinário } \\
\text { e sua relação com o } \\
\text { antibiograma em um } \\
\text { laboratório da região do } \\
\text { noroeste do paraná. }\end{array}$ & $\begin{array}{l}\text { Verificar a incidência de infecções } \\
\text { urinárias no ano de } 2017 \text { e a sua } \\
\text { relação com o antibiograma em um } \\
\text { laboratório da região do Noroeste } \\
\text { do Paraná }\end{array}$ & $\begin{array}{l}25 \text { uroculturas de pacientes, totalizando } 22 \text { resultados positivos, } \\
84 \% \text { eram do sexo feminino e } 16 \% \text { do sexo masculino. Os mais } \\
\text { acometidos foram os idosos acima de } 60 \text { anos, dos } \\
\text { microrganismos isolados, a bactéria predominante foi } \\
\text { a Escherichia coli }(60 \%) \\
\text { da Klebsiellapneumoniae }(12 \%) \text {, Morganellamorganii }(4 \%) \text {, Ent } \\
\text { erococcus sp (4\%), Aeromonas hydrophila (4\%) e Citrobacter } \\
\text { koseri }(4 \%) \text {. }\end{array}$ \\
\hline Brasil, 2017. & $\begin{array}{l}\text { Medidas de Prevenção de } \\
\text { Infecção Relacionada à } \\
\text { Assistência à Saúde. }\end{array}$ & $\begin{array}{l}\text { Medidas para a prevenção e } \\
\text { controle de infecções nos serviços } \\
\text { de saúde, devendo estar facilmente } \\
\text { disponível aos profissionais que } \\
\text { atuam nestes serviços. }\end{array}$ & $\begin{array}{l}\text { Contribuir para reduzir a incidência das IRAS em serviços de } \\
\text { saúde, oferece um importante instrumento de apoio para a } \\
\text { prevenção e redução das principais IRAS, como as Pneumonias, } \\
\text { Trato Urinário, Corrente Sanguínea e Sítio Cirúrgico, } \\
\text { contribuindo para a redução de riscos nos serviços de saúde do } \\
\text { Brasil. }\end{array}$ \\
\hline $\begin{array}{l}\text { Costa et al., } \\
2019 .\end{array}$ & $\begin{array}{l}\text { Infecção do trato urinário } \\
\text { causada por escherichia } \\
\text { coli: revisão de literatura. }\end{array}$ & $\begin{array}{l}\text { Infecções do trato urinário e seu } \\
\text { principal agente causador - a } \\
\text { bactéria Escherichia coli - relatando } \\
\text { os sinais e sintomas, fisio e } \\
\text { imunopatologia, diagnóstico e } \\
\text { prognóstico, tratamento e e } \\
\text { profilaxia, bem como } \\
\text { epidemiologia. }\end{array}$ & $\begin{array}{l}\text { A partir da revisão de literatura, foi possível notar que a } \\
\text { Escherichia coli é responsável pelo desenvolvimento de vários } \\
\text { tipos de doenças. Uma das mais prevalentes na sociedade é a } \\
\text { infecção do trato urinário. A gravidade do caso varia de acordo a } \\
\text { imunidade do hospedeiro, da carga bacteriana e do fator de } \\
\text { virulência. }\end{array}$ \\
\hline $\begin{array}{l}\text { Fernandes et } \\
\text { al., 2015. }\end{array}$ & $\begin{array}{l}\text { Relevância do diagnostico } \\
\text { e tratamento da infecção do } \\
\text { trato urinário em gestantes: } \\
\text { uma revisão da literatura. }\end{array}$ & 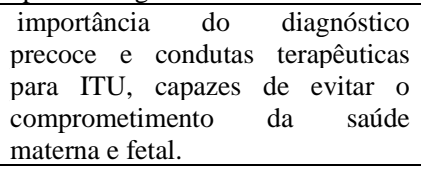 & $\begin{array}{l}\text { A maioria dos estudos apontaram Escherichia coli como o } \\
\text { principal causador de ITU, estando associada à cerca de } 70 \% \text { a } \\
80 \% \text { dos casos. }\end{array}$ \\
\hline $\begin{array}{l}\text { Ferreira et al., } \\
2019 .\end{array}$ & $\begin{array}{l}\text { Perfil de resistência de } \\
\text { bactérias isoladas em } \\
\text { infecções do trato urinário } \\
\text { em pacientes idosos no } \\
\text { período de } 2015 \text { em um } \\
\text { hospital universitário do } \\
\text { Rio Grande do Norte. }\end{array}$ & $\begin{array}{l}\text { Verificar o perfil de resistência do } \\
\text { microrganismo causador de } \\
\text { infecção urinaria mais prevalente } \\
\text { em idosos, em um Hospital } \\
\text { Universitário do Rio Grande do } \\
\text { Norte. }\end{array}$ & $\begin{array}{l}\text { A faixa etária variou de } 63 \text { até } 89 \text { anos. O sexo mais acometido } \\
\text { foi o masculino com } 8 \text { casos. O patógeno mais frequente isolado } \\
\text { a Escherichia coli representou } 31,3 \% \text {. testes de resistência paras } \\
\text { as cepas de E. coli isoladas das infecções, os antimicrobianos que } \\
\text { apresentaram grandes porcentagens de resistência foram: a } \\
\text { ciprofloxacino, seguido de norfloxacino, levofloxacino, ácido } \\
\text { nalidixico, sulfametoxazol + trimetropima e a ampicilina. }\end{array}$ \\
\hline Freire, 2019 & $\begin{array}{l}\text { Identificação e prevalência } \\
\text { de bactérias causadoras de } \\
\quad \text { infecções } \\
\text { urinárias nosocomiais em } \\
\text { um hospital universitário } \\
\text { do rio grande do Norte } \\
\text { entre os anos de } 2015 \text { a } \\
\quad 2017 \\
\end{array}$ & $\begin{array}{lrr}\text { Avaliar a } & \text { epidemiologia das } \\
\text { culturas de } & \text { urina de origem } \\
\text { nosocomial, } & \text { resultados de } \\
\text { antibiograma } & \text { dos principais } \\
\text { patógenos. } & & \end{array}$ & $\begin{array}{l}\text { Estudos que intensifiquem o conhecimento da prevalência dos } \\
\text { uropatógenos da região, seu perfil de resistência aos } \\
\text { antimicrobianos, o sexo e a faixa etária que mais são acometidos, } \\
\text { possibilitando melhor alternativa para o tratamento do paciente. }\end{array}$ \\
\hline Lo et al., 2018. & $\begin{array}{l}\text { Aspectos clínicos e } \\
\text { laboratoriais da infecção } \\
\text { do trato urinário em } \\
\text { lactentes jovens. }\end{array}$ & $\begin{array}{l}\text { Descrever aspectos clínicos, } \\
\text { demográficos e laboratoriais de } \\
\text { ITU em lactentes } \leq 3 \text { meses. }\end{array}$ & $\begin{array}{l}\text { Das } 519 \text { uroculturas colhidas, confirmou-se } 65 \text { casos de ITU } \\
\text { (prevalência: } 12,5 \%) \text {, com predomínio em meninos }(77 \%) \text {. As } \\
\text { etiologias mais frequentes foram Escherichia coli }(56,9 \%) \text {, } \\
\text { Klebsiella pneumoniae }(18,5 \%) \text { e Enterococcus faecalis }(7,7 \%) \text {. } \\
\text { Os sintomas mais frequentes foram febre }(77,8 \%) \text {, irritabilidade } \\
(41,4 \%) \text { e vômitos }(25,4 \%) \text {. }\end{array}$ \\
\hline $\begin{array}{l}\text { Lopes et al., } \\
2018 .\end{array}$ & $\begin{array}{l}\text { Assistência de enfermagem } \\
\text { ao paciente acometido com } \\
\text { infecção do trato urinário } \\
\text { por uso de sonda vesical de } \\
\text { demora: uma revisão de } \\
\quad \text { literatura. }\end{array}$ & $\begin{array}{l}\text { Estabelecer a incidências e os } \\
\text { fatores de risco que geram a } \\
\text { infecção do trato urinário em } \\
\text { pacientes submetidos a introdução } \\
\text { de sonda vesical de demora. }\end{array}$ & $\begin{array}{l}\text { Técnicas assépticas para a prevenção da ITU, do conhecimento } \\
\text { teórico, dos limites e possibilidades na pratica de sua inserção do } \\
\text { cateter, colocando em práticas medidas preventivas que } \\
\text { minimizam os riscos de infecção urinaria provenientes da sonda } \\
\text { vesical de demora (SVD). }\end{array}$ \\
\hline $\begin{array}{l}\text { Machado et al., } \\
2016 .\end{array}$ & $\begin{array}{l}\text { Análise de resultados de } \\
\text { urocultura e antibiograma } \\
\text { em amostras suspeitas de }\end{array}$ & $\begin{array}{l}\text { Identificar os microrganismos, a } \\
\text { resistência aos principais } \\
\text { antimicrobianos utilizados em }\end{array}$ & $\begin{array}{l}\text { O agente etiológico mais frequente foi Escherichia coli. Entre os } \\
\text { antimicrobianos mais resistentes estão a Ampicilina, Ácido } \\
\text { Nalídixico, Sulfazotrim, Tetraciclina e Cefazolina }\end{array}$ \\
\hline
\end{tabular}




\begin{tabular}{|c|c|c|c|}
\hline & $\begin{array}{c}\text { infecção urinária em Barra } \\
\text { do Garças - MT. }\end{array}$ & $\begin{array}{l}\text { pacientes atendidos em um } \\
\text { Laboratório particular de Barra do } \\
\text { Garças, MT }\end{array}$ & eCiprofloxacino. \\
\hline $\begin{array}{l}\text { Mendes et al., } \\
2021 .\end{array}$ & $\begin{array}{l}\text { Revisão integrativa: } \\
\text { método de pesquisa para a } \\
\text { incorporação de evidências } \\
\text { na saúde e na enfermagem. }\end{array}$ & $\begin{array}{l}\text { Apresentar os conceitos gerais e as } \\
\text { etapas para a elaboração da revisão } \\
\text { integrativa, bem como aspectos } \\
\text { relevantes sobre a aplicabilidade } \\
\text { deste método para a pesquisa na } \\
\text { saúde e enfermagem. }\end{array}$ & $\begin{array}{l}\text { A revisão integrativa oferece aos profissionais de diversas áreas } \\
\text { de atuação na saúde o acesso rápido aos resultados relevantes de } \\
\text { pesquisas que fundamentam as condutas ou a tomada de decisão, } \\
\text { proporcionando um saber crítico. }\end{array}$ \\
\hline Nóbrega, 2015. & $\begin{array}{l}\text { Bacteriúria em mulheres } \\
\text { após estudo } \\
\text { urodinâmico: fatores de } \\
\text { risco e análise } \\
\text { microbiológica. } 2015 \text {. }\end{array}$ & $\begin{array}{l}\text { Determinar os fatores de risco para } \\
\text { complicações infecciosas após o } \\
\text { estudo urodinâmico (UDS) em } \\
\text { mulheres, o que pode ajudar os } \\
\text { médicos a identificar indivíduos de } \\
\text { alto risco que se beneficiariam com } \\
\text { a profilaxia antibiótica antes do } \\
\text { UDS. }\end{array}$ & $\begin{array}{l}232 \text { de } 257 \text { mulheres foram submetidas a uma análise } \\
\text { posterior. A incidência de bacteriúria, bacteriúria transitória e } \\
\text { ITU após UDS foi de } 11,6 \%, 7,3 \% \text { e } 4,3 \% \text {, respectivamente. Na } \\
\text { análise multivariada, hipotireoidismo }(\mathrm{P}=0,04) \text {, índice de massa } \\
\text { corporal (IMC)>30 }(\mathrm{P}=0,025) \text { e prolapso de órgão pélvico } \\
\text { avançado }(\mathrm{P}=0,021) \text { foram associados a um risco } \\
\text { significativamente aumentado de bacteriúria; no entanto, apenas } \\
\text { IMC }>30(\mathrm{P}=0,02) \text { foi associado a um risco aumentado de ITU. }\end{array}$ \\
\hline
\end{tabular}

Fonte: Autores (2021).

\section{a. Gênero e a faixa etária mais afetada na população}

Considerada uma doença infecciosa comum, a ITU apresenta variadas patologias. Segundo Silva \& Santos (2019) a ocorrência dessa doença é de aproximadamente 130-175 milhões no mundo, atingindo homens e mulheres. 40\% das mulheres pode desenvolver esta infecção em alguma época da sua vida, principalmente durante a gravidez. No Brasil, as ITUs ocorrem na proporção de 80 para 1.000 consultas clínicas.

Estudos de Costa et al. (2019) apresentam porcentagem com variações de 82,1\% a 85,2\% respectivamente, desse tipo de UTI em mulheres. Tais achados reforçam a pesquisa desenvolvida por Nogueira (2020) que aponta que as mulheres adultas têm aproximadamente 50 vezes mais chances de adquirir ITU do que os homens. Conforme se verifica, os casos são mais prevalentes em mulheres, porém, em homens, esse risco aumenta principalmente na faixa etária acima de 50 anos, provavelmente por problemas relacionados a próstata, na qual apresenta um comprometimento da atividade bactericida do fluido prostático (Freire, 2019).

Resultados de estudo desenvolvido por Weinberg (2018) mostraram que de 1 a $2 \%$ dos meninos até 6 anos de idade apresentaram sintomas ou tiveram ITU; 3 a 7\% de mulheres já apresentaram sintomas ou tiveram essa infecção. O pico da idade da ITU é distinto, e possui uma fase de lactância entre um e outro de 2 e 4 anos (para a maioria das crianças, na ocasião do treinamento da higiene). Em meninas, as infecções geralmente são ascendentes e causam bacteremia com uma frequência menor. Outros fatores determinantes para as crianças são a prematuridade, cateteres urinários de demora e obstruções e malformações do trato urinário.

\section{b. Principais agentes causadores da ITU}

A ITU é determinada como a presença de bactérias que podem causar doenças no trato urinário feminino. A ITU pode ser demonstrada pela invasão bacteriana em algumas estruturas do sistema urinário ou por colonização sem evidência de urina, mas sem invasão de tecido, quando a infecção é assintomática (Resende et al., 2016).

O trato urinário feminino, conforme mostra a Figura 2 é formado pelos seguintes órgãos: dois rins, dois ureteres, a bexiga urinária e a uretra. Esses órgãos atuam de maneira conjunta, garantindo a filtração do sangue, a produção da urina e sua eliminação. 
Figura 2 - Sistema urinário feminino.

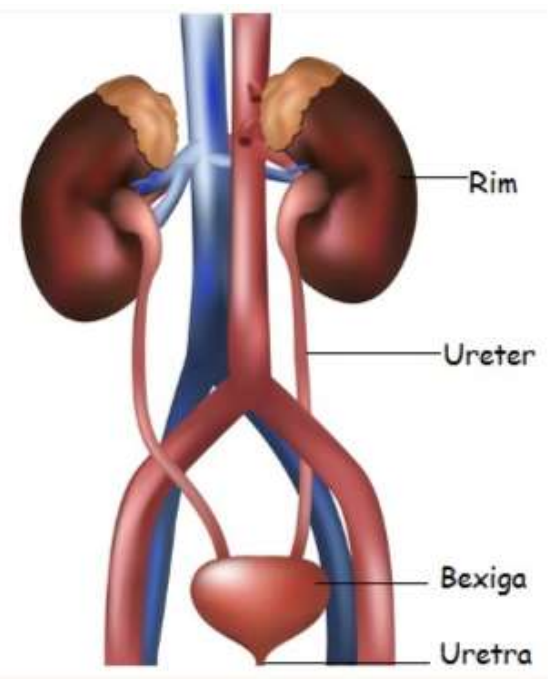

Fonte: Aires (2017).

O sistema urinário, mostrado na Figura 2, é responsável pela produção, armazenamento temporário e eliminação da urina. Nesse sentido, torna-se necessário entender as funções de cada órgão do sistema urinário feminino, visto que todos devem estar desenvolvendo suas funções normalmente. Os rins são responsáveis pela produção da urina; os ureteres são ductos que levam a urina do rim para a bexiga; a bexiga é o órgão responsável pelo armazenamento da urina até sua eliminação; e a uretra, é o órgão que garante a eliminação da urina para fora do corpo (Aires, 2017).

Lopes et al. (2018) afirmam que alguns fatores podem estar relacionados com a origem da ITU, como o comprimento da uretra, a vida sexualmente ativa, o uso de contraceptivo e espermicida, a menopausa (alterações hormonais), bloqueio o trato urinário (pedra nos rins e aumento da próstata), deficiência no sistema imunológico ou a utilização de cateter ou sonda. A deficiência de higiene, as falhas relacionadas à prescrição de medicamentos e a interrupção do tratamento, também colaboram com a recorrência da mesma.

Segundo Assis et al. (2019) as infecções urinárias são causadas por diversos microrganismos tais como fungos e bactérias, sendo mais prevalentes as Gram-negativas, dentre as quais a E. coli é o invasor mais comum, sendo isolada em 70 a 90\% das infecções agudas de origem bacteriana. Contudo, outras também podem estar associadas às ITUs, tais como: Pseudomonas sp., Proteus sp., Klebsiella pneumoniae, Enterobacter sp., Streptococcus sp., e Proteus sp., e Staphylococcus saprophyticus, sendo esta última a segunda causa mais frequente desta infecção.

Sobre os agentes causadores de ITUs, Brambilla e Becker. (2019) citam que estas podem ocorrer por meio de infecções divididas em trato urinário superior e inferior. A camada inferior afeta a uretra e a bexiga, e a camada superior afeta os ureteres, a pelve renal e os rins. Podem se originar na bexiga e chegar aos rins através dos ureteres. Quando isso ocorre, é denominado ITU superior.

A via mais comum de ITU é a via ascendente, ou seja, as bactérias que colonizam o períneo infectam principalmente o trato inferior, bexiga (cistite) e uretra (uretrite) e migram para o trato superior, causando danos ao os rins (pielonefrite), ureter (ureterite) e pelve renal (pielite) (Lo et al., 2018).

$\mathrm{Na}$ infecção pela via ascendente, as bactérias podem atingir uretra, bexiga, ureter e rins. Braggiato e Lazar (2016) ressaltam que devido a curta distância da uretra, essa via ocorre frequentemente em mulheres ou em pacientes que realizam exame de dispositivo do trato urinário. A via sanguínea é a principal via de desenvolvimento neonatal, conforme evidenciado pela forte formação de vasos sanguíneos nos rins. Por outro lado, a via linfática é rara e os microrganismos podem chegar ao rim pelos vasos linfáticos entre o intestino e o rim ou entre o trato inferior e superior. 
As ITUs podem ser divididas da seguinte forma segundo a topografia (Brasil, 2017): Baixas: aquelas que envolvem o epididimo (epididimite) e a prostata (prostatite) nos homens, e nas mulheres envolvem uretra (uretrite) e a bexiga (cistite). Altas: aquelas que envolvem os ureteres (ureterites) ou parenquima renal (pielonefrite). As ITUs podem ser agrupadas em quatro entidades clínicas, sendo inter-relacionadas segundo a localização da infecção em bacteriúria assintomática (urina), uretrite (infecção na uretra), cistite (infecção na bexiga) e pielonefrite (infecção nos rins) (Costa et al., 2019).

\section{c. Sensibilidade e resistência das bactérias causadoras da infecção aos agentes antibacterianos}

Estudo de Elias e Ribeiro (2017), analisou 592 uroculturas positivas e encontrou os seguintes resultados: E. coli 39,10\%, Klebisiella sp. (15,90\%), Proteus mirabilis (5,30\%), Enterococus fecalis $(5,20 \%)$ e Cândida tropicalis (3,50\%). Machado et al. (2016) identificaram um maior crescimento de E. coli $(67,2 \%)$ nas uroculturas.

A E. coli é prevalente na flora intestinal, podendo também colonizar a mucosa genital. Em determinadas situações pode penetrar no sistema urinário, através do canal uretral, aderir e colonizar a mucosa urogenital (utilizando fímbrias e adesinas). É capaz de resistir à eliminação pelo fluxo urinário causando uma bacteriúria acentuada (Fernandes et al., 2015).

Os dados apresentados nos trabalhos citados acima mostram que a E. coli é um patógeno com alta representatividade em uroculturas, o que demonstra a importância deste microrganismo para a saúde pública. Outro aspecto importante a ser considerado nos microrganismos patogênicos, é a resistência que estes adquirem aos antibióticos utilizados no tratamento das ITU.Conforme já mencionado, a E. coli é um bacilo Gram-negativo, fermentador de carboidratos e anaeróbio facultativo, comumente encontrada comumente na flora intestinal. Regularmente essa bactéria é retratada como causadora de ITU em virtude da capacidade de criar comunidades biológicas em cateteres urinários e/ou em outro dispositivo médico implantáveis (Trabulsi \& Alterthum, 2015).

A Figura 3 a seguir, apresenta resultados do estudo desenvolvido Freire (2019) sobre a sensibilidade a antibióticos apresentadas por pacientes internados em uma unidade hospitalar no Rio Grande do Norte.

Figura 3 - Perfis de sensibilidade dos antibióticos isoladas das uroculturas de pacientes internos no HUAB do RN no período de janeiro a dezembro 2015 a 2017.

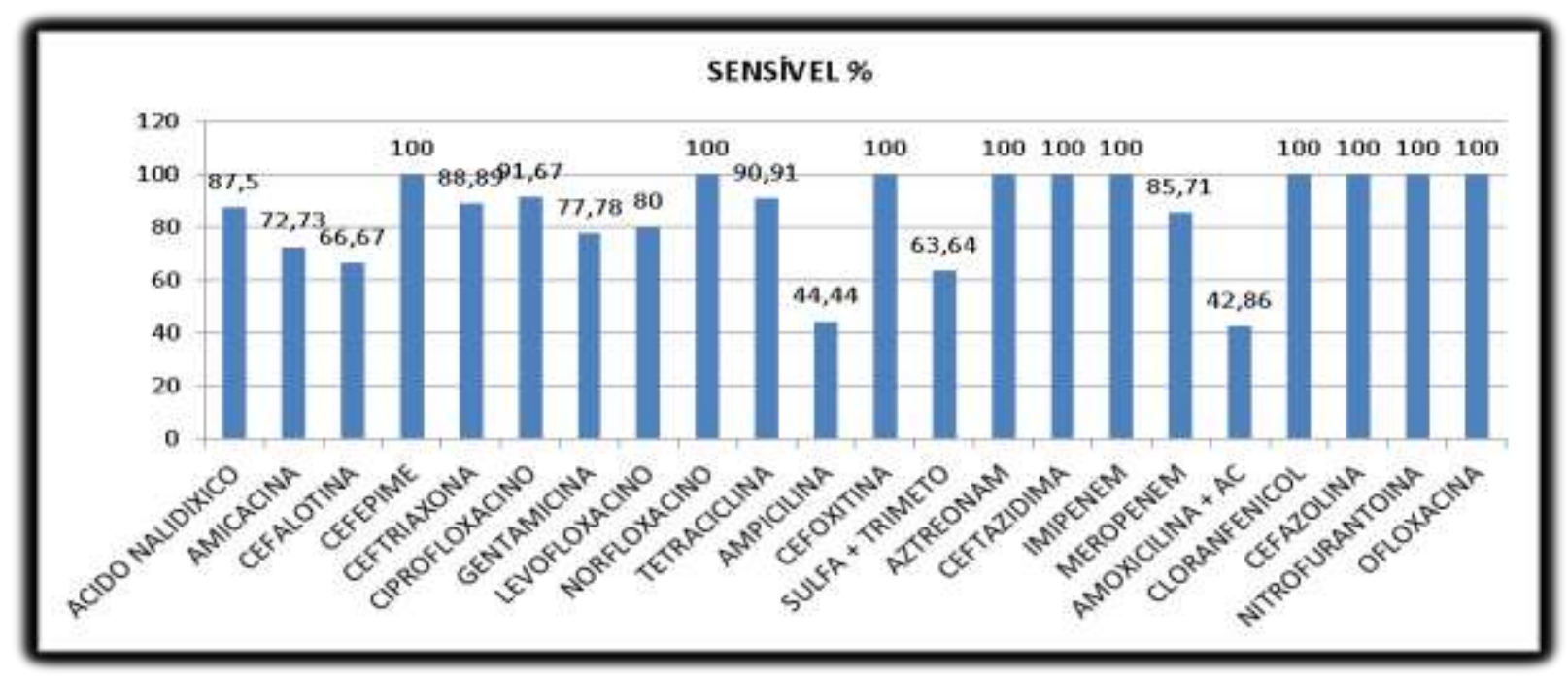

Fonte: Freire (2019).

Pode-se observar na Figura 3, há uma sensibilidade maior para Cefepime (100\%), Ciprofloxacino (91,67\%) e Tetraciclina $(90,91 \%)$, o que pode-se sugerir que esses microrganismos provavelmente são identificados como produtores de algum tipo de enzima beta-lactamase, entretanto são sensíveis a outros antibióticos que agem na parede celular bacteriana. 
Na Figura 4 a seguir, mostra os resultados obtidos por Freire (2019) em estudo sobre a resistência a antibióticos apresentadas por pacientes internados em uma unidade hospitalar no Rio Grande do Norte.

Figura 4 - Perfis de resistência dos antibióticos isoladas das uroculturas de pacientes internos no HUAB do RN no período de janeiro a dezembro 2015 a 2017.

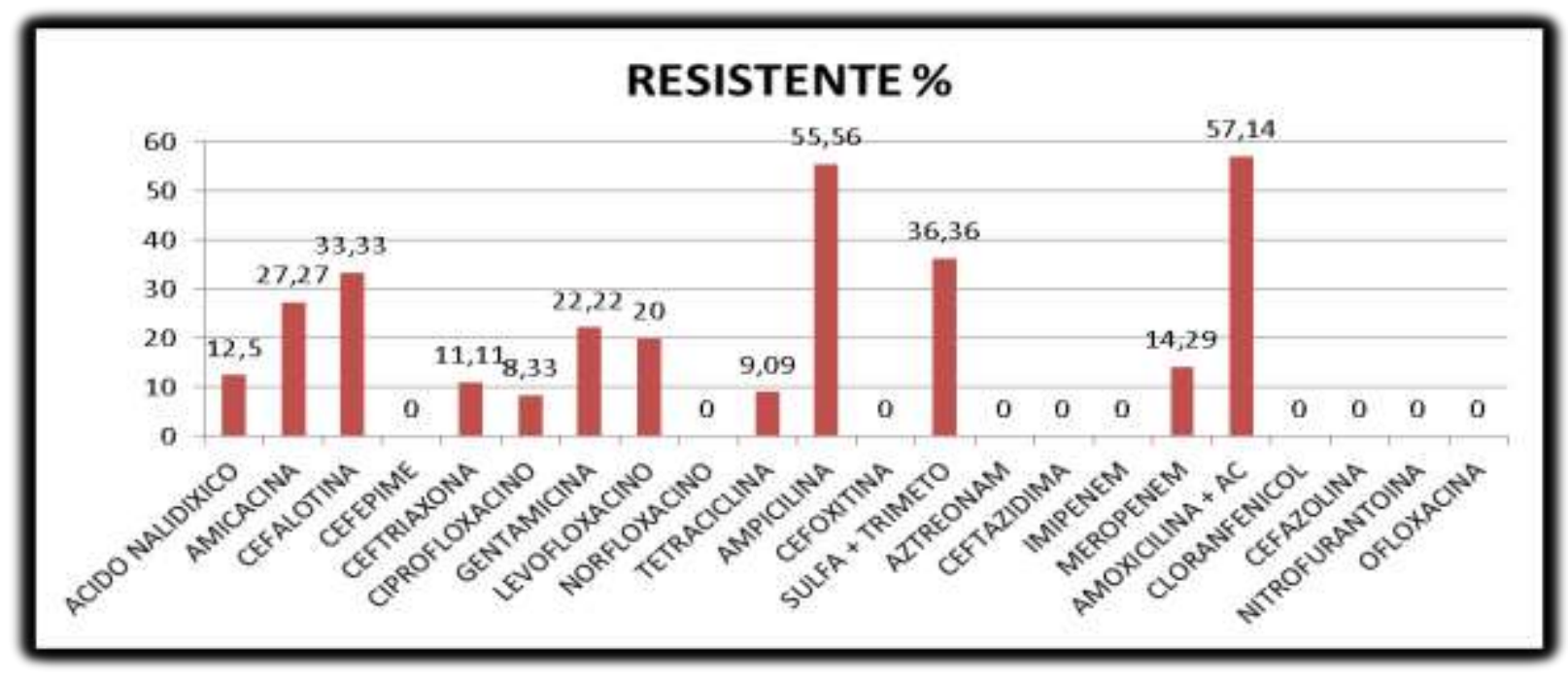

Fonte: Freire (2019).

Tomando por parâmetro os resultados de estudos desenvolvidos por Freire (2019) conforme mostrado na Figura 4 acima, a maior resistência foi principalmente para a Amoxicilina + Ácido Clavulânico (57,14\%) e Ampicilina (55,56\%).

Para Ferreira et al. (2019) a resistência frente a antimicrobianos betalactâmicos, como a ampicilina, pode ser explicado pelo uso intensivo na saúde humana. A baixa resistência frente ao cefepime, implica que seu uso é ainda moderado nas prescrições. As resistências aos antimicrobianos quinolonas, ácido nalidixico, ciprofloxacina e norfloxacina, são motivos de preocupação. A resistência de E. coli a ciprofloxacina é preocupante, pois as quinolonas são os medicamentos mais prescritos empiricamente para ITU. Ferreira et al. (2019) alerta que devido a elevadas resistências para a ciprofloxacina em Curitiba, em pacientes internados, requer monitoramento das resistências na região. As altas resistências verificadas para tetraciclina decorrem do uso intensivo feito na saúde humana e na produção animal. A disseminação de genes de resistência no ambiente também é outro fator que auxilia na manutenção dos índices de resistência verificados nas populações humanas.

Em outra pesquisa desenvolvida por Bello Fernández et al. (2019) ficou evidenciado que tanto para as bactérias Gram-positivas como para as Gram-negativas a resistência maior predominava para a Amoxicilina + Ácido Clavulânico, reforçando os dados apresentados.

Silva e Santos (2019), por sua vez, destacam a antibioticoterapia eficaz e adequada prescrita por um médico, ressaltando a necessidade de se conhecer o agente infeccioso e sua sensibilidade. No estudo, a sensibilidade mínima para indicar o uso empírico de um antibiótico para microrganismos específicos deve ser mais que $80 \%$.

Segundo Barbosa e Resende (2018), o uso incorreto e indiscriminado dos antibióticos para os tratamentos das infecções de urina poderá colaborar com o surgimento de cepas bacterianas resistentes, com episódios de recidiva e com o agravamento desta doença. É importante e necessário desestimular o uso desenfreado e a automedicação, bem como estimular cada vez mais a realização de exames urológicos no Brasil. Um fator que ainda limita a urocultura é a demora do procedimento para obtenção dos resultados, muito médicos iniciam o tratamento antes mesmo do resultado, dependendo do problema, dentre 
os quais: uma cistite branda, muitas vezes, o paciente já está curado antes mesmo de saírem seus resultados, nessas situações o resultado torna-se praticamente desnecessário (Assis et al., 2019).

Para a escolha do antibiótico correto, deve-se levar em consideração a eficácia clinica diante da bactéria causadora da infecção, prevalência da resistência local aquele antibiótico, além de avaliar o resultado da urocultura. Assim, é importante a antibioticoterapia eficaz e adequada prescrita por um médico. Para tanto, é preciso ter conhecimento sobre o agente infeccioso e sua sensibilidade. A sensibilidade mínima para indicar o uso empírico de um antibiótico para microrganismos específicos deve ser mais que $80 \%$ (Silva \& Santos (2019).

\section{Considerações Finais}

O estudo mostrou que dentre os agentes infecciosos da ITU o microrganismo E. coli é o que apresenta maior prevalência. Verificou-se, ainda, que durante o tratamento dessa infecção, em muitos casos, a taxa de resistência a antimicrobianos a taxa é elevada.

Em relação à resistência aos antimicrobianos para as cepas do E. coli, observou-se que muitos antimicrobianos apresentaram ótimos resultados de sensibilidade, com $100 \%$ de eficácia contra as cepas como a ceztazidima, e outros antibacterianos com bons resultados como cefepime, gentamicina e amicacina. Na identificação dos testes de resistência para as cinco cepas de E. coli isoladas, os seguintes antimicrobianos apresentaram grandes porcentagens de resistência destacandose a ciprofloxacino, norfloxacino, levofloxacino, ácido nalidixico, sulfametoxazol + trimetropima e a ampicilina.

Face ao exposto, é necessário que se padronize metodologias para utilizar os antimicrobianos certos, a fim de fazer urocultura junto ao antibiograma com a intenção de identificar os causadores de infecção urinária e diminuir a resistência bacteriana.

Ressalta-se que o uso correto e a devida orientação sobre como usar antibióticos são muito importantes e a conscientização dos profissionais e da população sobre o uso racional, principalmente os antibióticos de amplo espectro, como as quinolonas, diminuindo a pressão na escolha dos antibióticos. É necessário também entender o estado da resistência em pacientes e internados com ITU, pois é de suma importância monitorar as ações de resistência e evitar prescrições que não tenham um espectro antimicrobiano.

Para tanto, é imprescindível que se realize periodicamente estudos epidemiológicos, pois as informações sobre o aumento de resistência a antibióticos variam bastante. Assim, o diagnóstico correto é fundamental para evitar o uso irregular e descontrolado desses medicamentos. Por fim, diante da grande prevalência de sensibilidade e resistência das bactérias causadoras de ITU aos agentes antibacteriano, identificadas neste trabalho, sugere-se que os laboratórios invistam em estudos do perfil de resistência genético para criar mecanismos de entendimento do comportamento da resistência bacteriana no ambiente hospitalar e como isso pode afetar o ambiente comunitário. É importante, também, que se desenvolvam estudos que estabeleçam a prevalência dos uropatógenos locais, assim como seu perfil de sensibilidade.

\section{Referências}

Aires, M. M. (2017). Fisiologia. (4a ed.), Guanabara Koogan.

Assis, T. et al. (2019). A incidência de infecções no trato urinário: uma análise documental de prontuários. Rev. Bra. Edu. Saúde, 8(4), 58-64, https://www.gvaa.com.br/revista/index.php/REBES/article/view/6115.

Barberino, M. G M. A. (2010). Prevalência de Resistência a Antimicrobianos e Uso de Testes Rápidos no Diagnóstico das Infecções do Trato Urinário Adquiridas na Comunidade. Dissertação (Mestrado) - Curso de Biotecnologia em Saúde e Medicina Investigativa, Centro de Pesquisa Gonçalo Moniz, Fundação Osvaldo Cruz, Salvador. https://www.arca.fiocruz.br/bitstream/icict/4251/1/Maria\%20Goreth.\%20Preval\%C3\%AAnci a\%20de\% 20Resist\%C3\%AAncia \%20a\%20Antimicrobianos\%20e.pdf.

Barbosa, J.C.S. \& Resende, F.A. (2018). Perfil do uso indiscriminado de medicamento da cidade de Cordisburgo-MG. Revista Brasileira de Ciências da Vida. Cordisburgo, 6(3). https://www.fvj.br/revista/wp-content/uploads/2019/11/2_IS_20181.pdf. 
Research, Society and Development, v. 10, n. 15, e556101523567, 2021

(CC BY 4.0) | ISSN 2525-3409 | DOI: http://dx.doi.org/10.33448/rsd-v10i15.23567

Brasil. Agência Nacional de Vigilância Sanitária. (2017). Medidas de Prevenção de Infecção Relacionada à Assistência à Saúde. Anvisa.

Costa, I.A.C. et al. (2019). Infecção do trato urinário causada por escherichia coli: revisão de literatura. Salusvita, Bauru, 38(1), 155-193.

Fachin, O. (2017). Fundamentos de Metodologia. (6a ed.), Saraiva.

Fernandes, F.A. et al. (2015). Relevância do diagnostico e tratamento da infecção do trato urinário em gestantes: uma revisão da literatura. $C \& D-R e v i s t a$ Eletrônica da Fainor. Vitória da Conquista, 8(1), 54-70.

Ferreira, F. E. S. et al. (2019). Perfil de resistência de bactérias isoladas em infecções do trato urinário em pacientes idosos no período de 2015 em um hospital universitário do Rio Grande do Norte. IV Congresso Internacional de Envelhecimento Humano https://editorarealize.com.br/editora/ anais/cieh/2019/TRABALHO_EV125_MD1_SA11_ID2359_27052019232437.

Freire, M. T. J. (2019). Identificação e prevalência de bactérias causadoras de infecções urinárias nosocomiais em um hospital universitário do Rio Grande do Norte entre os anos 2015 a 2017. Trabalho de Conclusão de Curso. Cuité: CES. 68 p.

Gil, A. C. (2019). Métodos e técnicas de pesquisa social. (7a ed.), Atlas.

Lo, D. S. et al. (2018) Aspectos clínicos e laboratoriais da infecção do trato urinário em lactentes jovens. Jornal Brasileiro de Nefrologia. 40(1), 66-72.

Lopes, T. V. L. et al. (2018) Assistência de enfermagem ao paciente acometido com infecção do trato urinário por uso de sonda vesical de demora: uma revisão de literatura. Revista de Trabalhos Acadêmicos Universo. São Gonçalo, 3(5), 236-261.

Machado, S. T. et al. (2016). Análise de resultados de urocultura e antibiograma em amostras suspeitas de infecção urinária em Barra do Garças - MT. Interdisciplinar: Revista Eletrônica da Univar, (1), 147-163.

Mendes, K. D. S. et al. (2008). Revisão integrativa: método de pesquisa para a incorporação de evidências na saúde e na enfermagem. Texto contexto Enfermagem, 2008. http://www.scielo.br/scielo.php?script=sci_arttext\&pid=S010407072008000400018.

Nóbrega, M. M. (2015). Bacteriúria em mulheres após estudo urodinâmico: fatores de risco e análise microbiológica. 2015. Dissertação (Mestrado) - Curso de Pesquisa em Cirurgia, Faculdade de Ciências Médicas da Santa Casa de São Paulo. 70 p.

Nogueira, Y. A. (2020). Investigação de aspectos clínico-epidemiológicos acerca da infecção urinária em gestantes: uma revisão integrativa. Faculdade Nova Esperança de Mossoró. Núcleo de Pesquisa e Extensão Acadêmica - Nupea, 35.

Pereira, C. S. R. \& Calhau, P. (2016). Escherichia Coli e Infecção Urinária Recorrente em Pediatria. Faculdade de Medicina de Lisboa, (12705), 1-19.

Piovesan, A. C. et al. (2015). Diretrizes Urologia. Sociedade Brasileira de Urologia.

Silva, A. M. \& Santos, C. P. (2019). Infecção do trato urinário associado ao uso de cateter vesical de demora em unidade de terapia intensiva: revisão da literatura. Trabalho de Conclusão de Curso. Centro Universitário de Anápolis - Unievangélica. Anápolis. p. 39.

Trabulsi, L.R. \& Alterthum, F. (2015). Microbiologia. (6a ed.), Editora Atheneu.

Weinberg, G.A. (2018). Infecção do trato urinário (ITU) em crianças. https://www.msdmanuals.com/pt-br/profissional. 